\title{
Efeito do Estresse Climático sobre os Parâmetros Produtivos e Fisiológicos de Ovinos Santa Inês Mantidos em Confinamento na Região Litorânea do Nordeste do Brasil ${ }^{1}$
}

\author{
José Neuman Miranda Neiva ${ }^{2}$, Maurício Teixeira ${ }^{3}$, Silvia Helena Nogueira Turco ${ }^{4}$, Sônia Maria \\ Pinheiro de Oliveira ${ }^{5}$, Arlindo de Alencar Araripe Noronha Moura ${ }^{5}$
}

\begin{abstract}
RESUMO - O presente estudo foi conduzido objetivando-se avaliar a influência do estresse climático sobre o desempenho produtivo e as respostas fisiológicas de ovinos da raça Santa Inês em confinamento. Foram avaliados dois ambientes (sombra e sol) e duas dietas com duas relações volumoso:concentrado (70C:30V: 70\% de concentrado e 30\% de volumoso; 30C:70V: 30\% de concentrado e 70\% de volumoso). Os animais mantidos à sombra e alimentados com dieta contendo alto teor de concentrado (70C:30V) apresentaram maior consumo de matéria seca (1258 g/animal/dia) e de proteína bruta ( $0,8 \%$ do peso vivo [PV] e $\left.18 \mathrm{~g} / \mathrm{PV}^{0,75}\right)$ e maior ganho de peso (247 g/animal/dia). A temperatura nos ambientes de sol e sombra durante a tarde foi de 32,1 e 30,6 $6^{\circ} \mathrm{C}$ e os valores do índice de temperatura e umidade (ITU), 82,3 e 81,1, respectivamente. Os animais alimentados com alto teor de concentrado (70C:30V) apresentaram maior freqüência respiratória (FR), tanto à sombra quanto ao sol (87 e $71 \mathrm{mov} / \mathrm{min}$, respectivamente). Durante a tarde, a temperatura retal (TR) dos animais foi maior $\left(39,1^{\circ} \mathrm{C}\right)$ que pela manhã $\left(38,9^{\circ} \mathrm{C}\right)$. Porém, a TR mais elevada $\left(39,3^{\circ} \mathrm{C}\right)$ foi observada nos animais mantidos à sombra e alimentados com alto percentual de concentrado (70C:30V). Independentemente do ambiente, os animais alimentados com alto teor de concentrado (70C:30V) apresentaram maior TR $\left(39,2^{\circ} \mathrm{C}\right)$ do que aqueles alimentados com reduzido teor de concentrado (30C:70V) $\left(38,8^{\circ} \mathrm{C}\right)$. O tipo de dieta teve efeito sobre a susceptibilidade dos animais ao estresse causado pelas condições ambientais críticas durante o experimento. Os animais da raça Santa Inês mostraram-se sensíveis ao estresse ambiental, uma vez que apresentaram menor desempenho produtivo, quando expostos a condições de ausência de sombra.
\end{abstract}

Palavras-chave: ambiente, cordeiros, desempenho, estresse térmico

\section{Effects of Environmental Stress on Physiological Parameters of Feedlot Sheep in the Northeast of Brazil}

ABSTRACT - A study was conducted to determine the effect of environmental stress on physiological criteria of feedlot sheep. Treatments consisted of two different housing conditions (shade and no shade) and two levels of concentrate in the diet: high concentrate (70\% of concentrate and 30\% of roughage-70C:30R); low concentrate (30\% of concentrate and 70\% of roughage-30C:70R). Animals raised under shade and fed a high concentrate diet (70C:30R) had greater dry mater intake (1258 g/animal/day) and crude protein ( $0.8 \%$ of body weight (BW) and $18 \mathrm{~g} / \mathrm{BW}^{0.75}$ ), as well as weight gain (247 g/animal/day). Air temperature in the afternoon was $30.6^{\circ} \mathrm{C}$, under shade, and $32.1^{\circ} \mathrm{C}$, under sun and values of temperature humidity index(THI), 82.3 and 81.1, respectively. Animals fed more concentrate (70C:30R) had also higher respiratory frequency (RF), either raised under shade (87 mov/min) or under the sun (71 mov/min.). Rectal temperature (RT) was higher in the afternoon $\left(39.1^{\circ} \mathrm{C}\right)$ than in the morning $\left(38.9^{\circ} \mathrm{C}\right)$, but animals raised under shade and fed diets with $70 \%$ concentrate (70C:30R) had the highest value of RT $\left(39.3^{\circ} \mathrm{C}\right)$. Regardless of type of housing conditions, the animals that received more concentrate (70C:30R) had greater rectal temperature $\left(39.2^{\circ} \mathrm{C}\right)$ than those fed a diet with less concentrate $(30 \mathrm{C}: 70 \mathrm{R})\left(38.8^{\circ} \mathrm{C}\right)$. Therefore, the type of diet influenced the response of the animals to housing conditions. Moreover, Santa Inês sheep are susceptible to environmental stress because had lower performance when raised under no shade.

Key Words: environment, heat stress, lambs, performance

\footnotetext{
${ }^{1}$ Parte da dissertação apresentada pelo segundo autor para a conclusão do curso de Mestrado em Zootecnia - UFC, parcialmente financiada pela FUNCAP.

2 Zootecnista, Dr, Professor do Depto. de Zootecnia da Universidade Federal do Ceará, Caixa Postal 12168, CEP: 60970-355, FortalezaCE. E.mail: zeneuman@ufc.br

${ }^{3}$ Engenheiro-Agrônomo, MS, Banco do Nordeste, Bolsista da FUNCAP. E.mail: mauriciot@bnb.gov.br

${ }^{4}$ Engenheira Agrícola, Dr, Professora da Universidade Estadual da Bahia. E.mail: silviaturco@bol.com.br

${ }^{5}$ Engenheiro-Agrônomo, Dr, Professor da Universidade Federal do Ceará. E.mail: soniace@ufc.br
} 


\section{Introdução}

A interação animal x ambiente deve ser considerada quando se busca maior eficiência na exploração pecuária, pois as diferentes respostas do animal às peculiaridades de cada região são determinantes no sucesso da atividade produtiva. Assim, a correta identificação dos fatores que influem na vida produtiva do animal, como o estresse imposto pelas flutuações estacionais do meio-ambiente, permitem ajustes nas práticas de manejo dos sistemas de produção, possibilitando dar-lhes sustentabilidade e viabilidade econômica. Dessa forma, o conhecimento das variáveis climáticas, sua interação com os animais e as respostas comportamentais, fisiológicas e produtivas são preponderantes na adequação do sistema de produção aos objetivos da atividade.

A temperatura do ar é considerada o fator climático com influência mais importante sobre o ambiente físico do animal (McDowell, 1974). Dentro de ampla faixa de temperatura, podem ser definidas zonas térmicas que proporcionam maior ou menor conforto ao animal. Os animais, para terem máxima produtividade, dependem de uma faixa de temperatura adequada, também chamada de zona de conforto térmico, em que não há gasto de energia ou atividade metabólica para aquecer ou esfriar o corpo. Do ponto de vista de produção, este aspecto reveste-se de muita importância, pelo fato de, dentro desses limites, os nutrientes ingeridos pelos animais serem utilizados exclusivamente para seu crescimento e desenvolvimento (Baêta \& Souza, 1997).

A umidade atmosférica é outra variável que influencia marcantemente o balanço calórico em ambientes quentes em que a perda de calor por evaporação é crucial à homeotermia (Young, 1988). Maior pressão de vapor devida à alta umidade do ar conduz à menor evaporação da água contida no animal para o meio, tornando o resfriamento do animal mais lento. Menor pressão de vapor, por sua vez, proporciona resfriamento do animal mais rapidamente, em decorrência da maior taxa de evaporação da água através da pele e do aparelho respiratório. Estas duas situações são encontradas em climas quente e úmido e quente e seco, respectivamente (McDowell, 1974).

O objetivo deste trabalho foi avaliar a influência do estresse ambiental sobre o desempenho produtivo e as respostas fisiológicas de ovinos da raça Santa Inês em confinamento, alimentados com dietas contendo diferentes níveis de concentrado.

\section{Material e Métodos}

O presente trabalho foi conduzido no Núcleo de Pesquisas em Forragicultura do Departamento de Zootecnia do Centro de Ciências Agrárias da Universidade Federal do Ceará, Fortaleza-CE, no período de 20 de outubro a 17 de dezembro de 1999. O município de Fortaleza-CE situa-se na zona litorânea, a 15,49m de altitude, 343'02'” de latitude sul e 38³2'35' ' de longitude oeste, apresentando temperaturas médias mínimas e máximas de $23,2^{\circ} \mathrm{C}$ e $30,2^{\circ} \mathrm{C}$, respectivamente, umidade relativa de $79 \%$ e radiação solar de $147.592 \mathrm{cal} / \mathrm{cm}^{2}$. O clima da região de fortaleza-CE, segundo Koepen, é do tipo AW'-Tropical chuvoso, com chuvas freqüentes no outono. Os dados climatológicos coletados durante o experimento estão apresentados na Tabela 1.

O ensaio foi desenvolvido em duas etapas, sendo a primeira de avaliação do desempenho produtivo e a segunda de avaliação de respostas bioclimatológicas.

Para o ensaio de desempenho produtivo, foram utilizados quarenta machos inteiros da raça Santa Inês com peso médio de $19 \mathrm{~kg}$, distribuídos em quatro tratamentos em um delineamento em blocos casualizados, com cinco repetições, adotando-se um esquema fatorial $2 \times 2$.

Os fatores estudados foram dois ambientes (sombra e sol) e dois níveis de ração concentrada (alto e baixo), que constituíram os seguintes tratamentos: T1 - animais mantidos à sombra, alimentados com dietas contendo $70 \%$ de ração concentrada e 30\% de volumoso; T2 - animais mantidos à sombra, alimentados com dietas contendo 30\% de ração concentrada e $70 \%$ de volumoso; T3 - animais mantidos ao sol, alimentados com dietas contendo $70 \%$ de ração concentrada e 30\% de volumoso; e T4 - animais mantidos ao sol, alimentados com dietas contendo $30 \%$ de ração concentrada e $70 \%$ de volumoso.

$\mathrm{O}$ ambiente de sombra consistiu de 10 baias de madeira com 2,5 m² cada, dispostas no sentido lesteoeste e em galpão coberto com telha de barro e pé direito de 3 metros. No ambiente de exposição ao sol as baias apresentavam as mesmas dimensões descritas anteriormente, porém ficavam em área gramada, dispostas no sentido norte-sul e foram construídas com tela de arame com malha de três polegadas e estacas com diâmetro máximo de sete centímetros, para se evitar sombreamento.

Como volumoso, utilizou-se feno de capimelefante, cortado com 50-60 dias de idade e produzido 
na Fazenda Experimental Vale do Curú, localizada em Pentecoste-CE. O feno apresentava 96,2\% de MS (Matéria Seca), 55,5\% de NDT (Nutrientes Digestíveis Totais), 6\% de PB (Proteína Bruta), 2,6\% EE (Extrato Etéreo) e 73,9\% de FDN (Fibra em Detergente Neutro). Já a ração concentrada apresentava $84,5 \%$ de NDT, $20 \%$ de PB, 4,4\% de EE e $22,2 \%$ de FDN, sendo composta de $67,3 \%$ de milho, 29,8\% de farelo de soja, 1,6 de premix mineral, $1,0 \%$ de sal comum e $0,3 \%$ de premix vitamínico.

A ração concentrada foi formulada após a análise bromatológica do feno de capim elefante, segundo metodologia descrita por Silva (1979), visando obter, na dieta com alto teor de ração concentrada, $75 \%$ de NDT e $16 \%$ de PB (base da matéria seca da dieta total). Assim, a dieta total, contendo $70 \%$ de concentrado, apresentou 76\% de NDT, 15,8\% de PB e 37,7\% de FDN e aquela contendo $30 \%$ de concentrado, $64 \%$ de NDT, $10,2 \%$ de PB e $58,4 \%$ de FDN. As dietas foram formuladas de acordo com o NRC (1985).

Foram avaliados os consumos de MS, PB, FDN e água, além do ganho de peso médio diário e conversão alimentar. Os consumos diários foram expressos em g/animal/dia, \% do peso vivo (PV) e g/UTM (unidade de tamanho metabólico $=\mathrm{PV}^{0,75}$ ).
Para o ensaio de avaliação dos parâmetros bioclimatológicos foram utilizados os mesmos animais do ensaio de desempenho (FASE I). Todavia, foi descartado, por sorteio, um animal de cada baia para se mensurar a temperatura retal e freqüência respiratória em menor espaço de tempo.

Diariamente, durante 17 dias, determinouse a temperatura retal e a frequência respiratória dos animais, às 7 h e 13 h30. Para obtenção dos dados climatológicos representativos dos dois ambientes (sombra e sol), foram instalados abrigos meteorológicos nas duas condições, ambos contendo termômetros de bulbo seco e bulbo úmido. A tomada das temperaturas ambientais foi realizada no momento da medição das variáveis fisiológicas.

O Índice de Temperatura e Umidade (ITU) e a umidade relativa do ar (UR) foram calculados de acordo com metodologia descrita por Baêta \& Souza (1997).

Os efeitos dos tipos de instalação (sol e sombra) e teor de concentrado da dieta sobre as variáveis dependentes foram avaliados pela análise de variância e pelo teste de média SNK(Student-Newman-Keuls) (SAS, 1996).

Tabela 1 - Valores para temperatura do ar, umidade relativa do ar e precipitação nos meses de outubro e novembro de 1999 em Fortaleza-CE

Table 1 - Air temperature, humidity and rain fall in October and November of 1999, in Fortaleza - Ceará

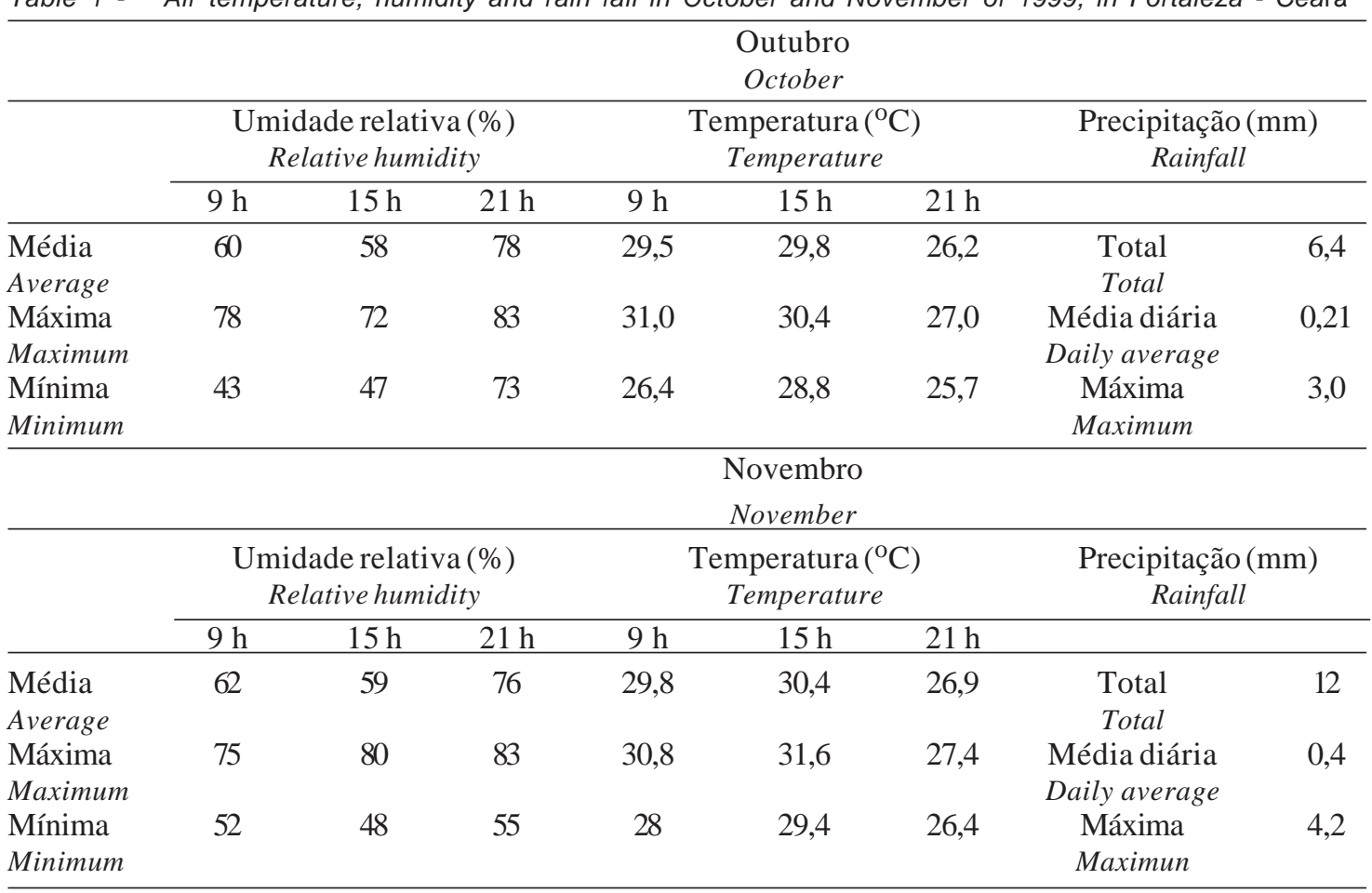

R. Bras. Zootec., v.33, n.3, p.668-678, 2004 


\section{Resultados e Discussão}

Ensaio de desempenho animal

O consumo de MS, expresso em g/animal/dia (Tabela 2), foi maior para os animais mantidos à sombra $(\mathrm{P}<0,05)$. Entretanto, não se detectou diferença significativa ( $\mathrm{P}>0,05)$, quando se expressou o consumo em $\%$ do peso vivo, tampouco em g/UTM. A provável justificativa para tal fato é que o consumo em g/animal/ dia não leva em consideração o peso corporal dos animais. Como o ganho de peso dos animais mantidos à sombra foi maior, estes apresentaram maior peso corporal ao longo do experimento e, obviamente, maior capacidade de ingestão, quando comparados aos mantidos ao sol. Já o consumo diário expresso em \% do peso vivo e em g/UTM corrige estas distorções, pois leva em conta o peso corporal dos animais.

Este resultado está de acordo com os dados obtidos por Brosh et al. (1998) e Mendes et al. (1976) que não encontraram diferença significativa no consumo de MS expresso em g/UTM e \%PV entre os animais mantidos à sombra e ao sol, independentemente do teor de energia da dieta.

Os animais alimentados com dieta contendo alto teor de ração concentrada (Tabela 2) apresentaram maior consumo de MS que aqueles recebendo dietas com baixo teor. Isso foi detectado quando o consumo foi expresso em g/animal/dia, não ocorrendo com o consumo expresso em \% do peso vivo e g/UTM, provavelmente pelo mesmo motivo descrito anteriormente.

Para o consumo de PB expresso em g/animal/dia, não se observou diferença significativa (Tabela 3) entre os animais mantidos sob as distintas condições ambientais (sol ou sombra). No entanto, quando o mesmo foi expresso em \% do peso vivo e em g/UTM, foram observadas diferenças significativas $(\mathrm{P}<0,05)$.

Estes resultados são opostos aos obtidos para consumo de MS, em que se observou maior consumo quando expresso em g/animal/dia e similaridade para os consumos expressos em \% peso vivo e g/UTM. Como pode-se observar, os animais tenderam a cor-

Tabela 2 - Consumo médio diário de matéria seca por ovinos da raça Santa Inês confinados sob sombra ou sol e alimentados com alto (AC) e baixo (BC) teor de ração concentrada

Table 2 - Average daily intake of dry mater by Santa Inês rams raised under two housing conditions (shade and sun) and fed high (HC) or low (LC) level of concentrate in the diet

\begin{tabular}{|c|c|c|c|c|c|c|}
\hline \multirow{3}{*}{$\begin{array}{l}\text { Consumo } \\
\text { Intake }\end{array}$} & \multicolumn{5}{|c|}{$\begin{array}{c}\text { Ambiente } \\
\text { Environment }\end{array}$} & \\
\hline & \multicolumn{2}{|c|}{$\begin{array}{l}\text { Sombra } \\
\text { Shade }\end{array}$} & \multicolumn{4}{|c|}{$\begin{array}{l}\text { Sol } \\
\text { Sun }\end{array}$} \\
\hline & $\begin{array}{l}\mathrm{AC} \\
\mathrm{HC}\end{array}$ & $\begin{array}{l}\mathrm{BC} \\
L C\end{array}$ & $\begin{array}{l}\text { Média } \\
\text { Average }\end{array}$ & $\begin{array}{l}\mathrm{AC} \\
\mathrm{HC}\end{array}$ & $\begin{array}{l}\mathrm{BC} \\
L C\end{array}$ & $\begin{array}{l}\text { Média } \\
\text { Average }\end{array}$ \\
\hline $\begin{array}{l}\text { g/animal/dia } \\
\text { g/animal/day }\end{array}$ & 1258 & 866 & 1062a & 1113 & 776 & $944 b$ \\
\hline $\begin{array}{l}\% \mathrm{PV} \\
\% L W\end{array}$ & 4,6 & 3,7 & $4,1 \mathrm{a}$ & 3,4 & 3,4 & $3,4 a$ \\
\hline $\begin{array}{l}\text { g/UTM } \\
g / M S U\end{array}$ & 105 & 81 & $93 a$ & 76 & 74 & $75 a$ \\
\hline \multirow{3}{*}{$\begin{array}{l}\text { Consumo } \\
\text { Intake }\end{array}$} & \multicolumn{5}{|c|}{$\begin{array}{c}\text { Teor de concentrado } \\
\text { Concentrate level }\end{array}$} & \\
\hline & \multicolumn{2}{|c|}{$\begin{array}{l}\mathrm{AC} \\
\mathrm{HC} \\
\end{array}$} & \multicolumn{4}{|c|}{$\begin{array}{l}\mathrm{BC} \\
L C\end{array}$} \\
\hline & $\begin{array}{c}\text { Sombra } \\
\text { Shade }\end{array}$ & $\begin{array}{l}\text { Sol } \\
\text { Sun }\end{array}$ & $\begin{array}{l}\text { Média } \\
\text { Average }\end{array}$ & $\begin{array}{l}\text { Sombra } \\
\text { Shade }\end{array}$ & $\begin{array}{l}\text { Sol } \\
\text { Sun }\end{array}$ & $\begin{array}{l}\text { Média } \\
\text { Average }\end{array}$ \\
\hline $\begin{array}{l}\text { g/animal/dia } \\
\text { g/animal/day }\end{array}$ & 1258 & 1113 & 1186a & 866 & 776 & $821 b$ \\
\hline $\begin{array}{l}\% \mathrm{PV} \\
\% L W\end{array}$ & 4,6 & 3,4 & $4,0 \mathrm{a}$ & 3,7 & 3,4 & 3,5a \\
\hline $\begin{array}{c}\text { g/UTM } \\
\text { g/MSU }\end{array}$ & 105 & 76 & $91 \mathrm{a}$ & 81 & 74 & $77 \mathrm{a}$ \\
\hline
\end{tabular}

R. Bras. Zootec., v.33, n.3, p.668-678, 2004 
rigir o consumo de MS, porém tal comportamento não foi suficiente para ajustar o nível de ingestão de nutrientes como a PB. Existe ainda a possibilidade de o estresse ambiental sofrido pelos animais expostos ao sol provocar alteração na seletividade do alimento e, dessa forma, impedir que os mesmos selecionassem uma dieta de melhor qualidade.

O consumo de PB diferiu significativamente entre os animais alimentados com dietas variando o teor de ração concentrada (Tabela 3), independentemente da condição de instalação, sendo que os animais alimentados com alto teor de concentrado apresentaram maior média de consumo de PB. A justificativa para tanto são os diferentes teores de PB das dietas totais com alto e baixo teor de ração concentrada, que apresentaram níveis protéicos de 15,8 e 10,2\% de PB respectivamente.

Para o consumo de FDN expresso em g/animal/ dia, \% do peso vivo e g/UTM nas duas condições ambientais (Tabela 4), não foram observadas dife- renças significativas $(\mathrm{P}>0,05)$. Estes resultados não confirmam a tendência dos animais em reduzir o consumo de forragem, quando submetidos ao estresse ambiental registrada por Bhattacharya \& Hussain (1974), que seria reflexo do consumo de FDN.

Quando expresso em g/animal/dia, o consumo de FDN dos animais alimentados com alto e baixo teor de ração concentrada na dieta (Tabela 4) não apresentou diferença significativa $(\mathrm{P}>0,05)$. No entanto, quando expresso em $\%$ do peso vivo e em g/UTM, foi observada diferença significativa, em que os animais alimentados com dietas contendo alto teor de concentrado apresentaram maior consumo $(\mathrm{P}<0,05)$.

Segundo Van Soest (1982), quando os animais se alimentam de dietas de menor valor nutricional, tendem a aumentar o consumo de FDN (\%PV e g/ UTM) para compensar a baixa disponibilidade de energia da dieta. Neste caso, fica claro que os animais consumiram alto volume de fibra em detergente neutro para compensar a menor qualidade da dieta.

Tabela 3 - Consumo médio diário de proteína bruta por ovinos da raça Santa Inês confinados sob sol ou sombra e alimentados com dietas contendo alto (AC) e baixo (BC) teor de ração concentrada

Table 3 - Average daily intake of crude protein by Santa Inês rams raised under two housing conditions (shade and sun) and fed high (HC) or low (LC) level of concentrate in the diet

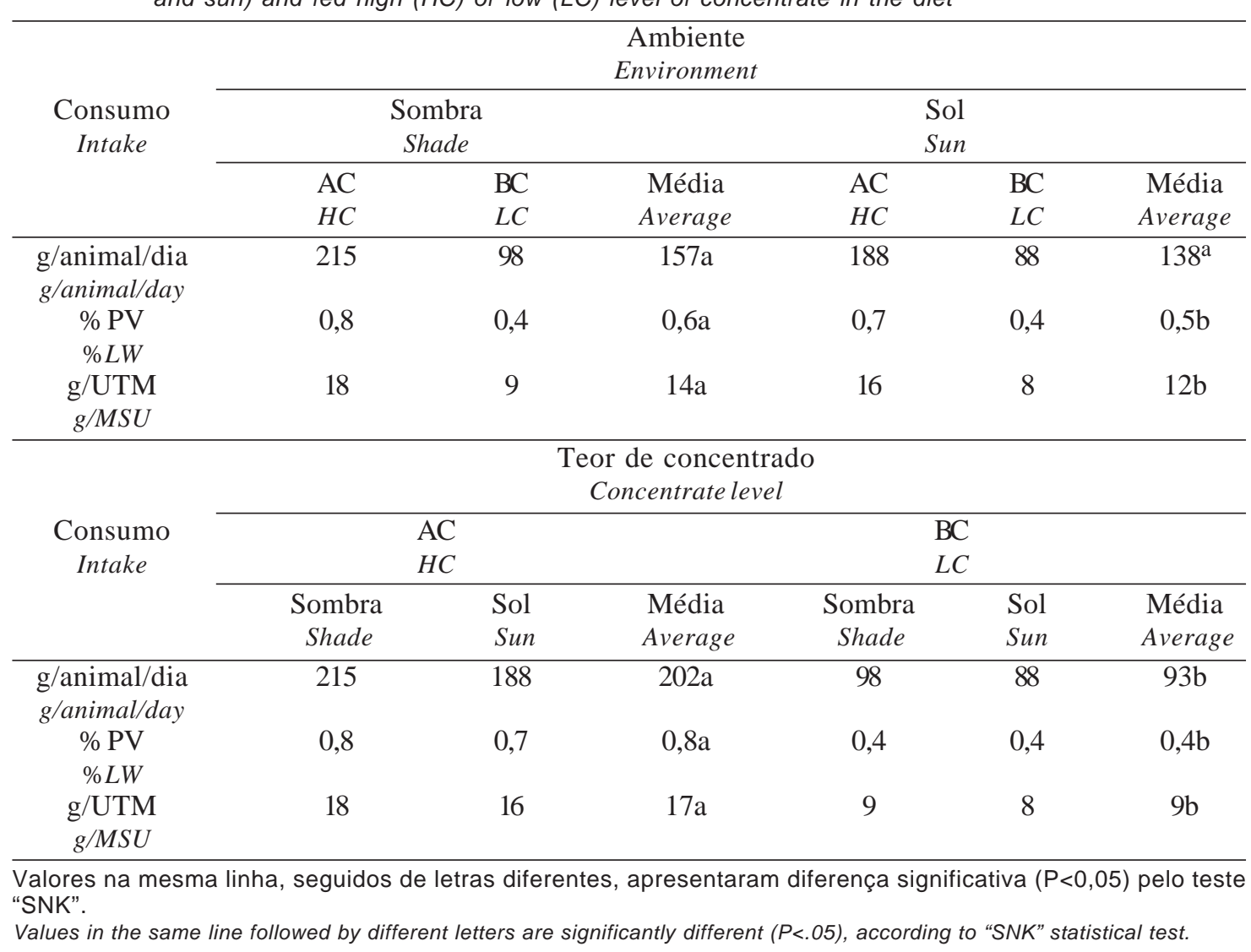

R. Bras. Zootec., v.33, n.3, p.668-678, 2004 
Os animais mantidos à sombra apresentaram consumo de água significativamente menor $(\mathrm{P}<0,05)$, que aqueles mantidos expostos à radiação solar direta (Tabela 5). Este fato ocorreu, provavelmente, como resposta à alta taxa de evaporação de água dos tecidos do animal, conseqüência das trocas de calor entre o animal e o ambiente.

Os resultados estão de acordo com os registrados por Bhattacharya \& Hussain (1974), Souto et al. (1990), Costa et al. (1992) e Padua \& Silva (1996), que observaram incremento no consumo de água, com o aumento da temperatura atmosférica.

O teor de ração concentrada na dieta também exerceu efeito sobre o consumo de água pelos animais (Tabela 5). Em razão de a dieta de alta energia ter proporcionado maior consumo de MS e de o consumo de água ter correlação positiva com o consumo de matéria seca, os dados coletados no presente trabalho confirmaram essa tendência.

Já Mendes et al. (1976) observaram aumento no consumo de água, devido ao aumento na temperatura ambiental, não se observando diferença significativa, em razão do efeito do nível de energia da dieta, diferindo dos resultados encontrados no presente trabalho. Outro registro que diferiu dos observados no presente trabalho foi o de Brosh et al. (1998), que observaram diferença significativa, devido ao efeito do nível de energia da dieta, mas não a verificou devido ao aumento da temperatura ambiente.

Os animais mantidos à sombra apresentaram ganho de peso (174 g/dia) aproximadamente 30\% maior $(\mathrm{P}<0,05)$ que aqueles mantidos recebendo radiação solar direta (122 g/dia) (Tabela 5), destacando a importância da instalação coberta (sombreamento) para se alcançar boa produtividade animal. Vale ressaltar que os maiores ganhos de peso foram obtidos com animais alimentados com dietas contendo alto teor de concentrado e mantidos à sombra (247 g/dia). Isso demonstra que mesmo animais de raças nativas, como a Santa Inês, necessitam de um mínimo de conforto ambiental para

Tabela 4 - Consumo médio diário de fibra em detergente neutro de ovinos da raça Santa Inês confinados sob sol ou sombra e alimentados com dietas contendo alto (AC) e baixo (BC) teor de ração concentrada

Table 4 - Average daily intake of neutral detergent fiber by Santa Inês rams raised under two housing conditions (shade and sun) and fed high (HC) or low (LC) level of concentrate in the diet

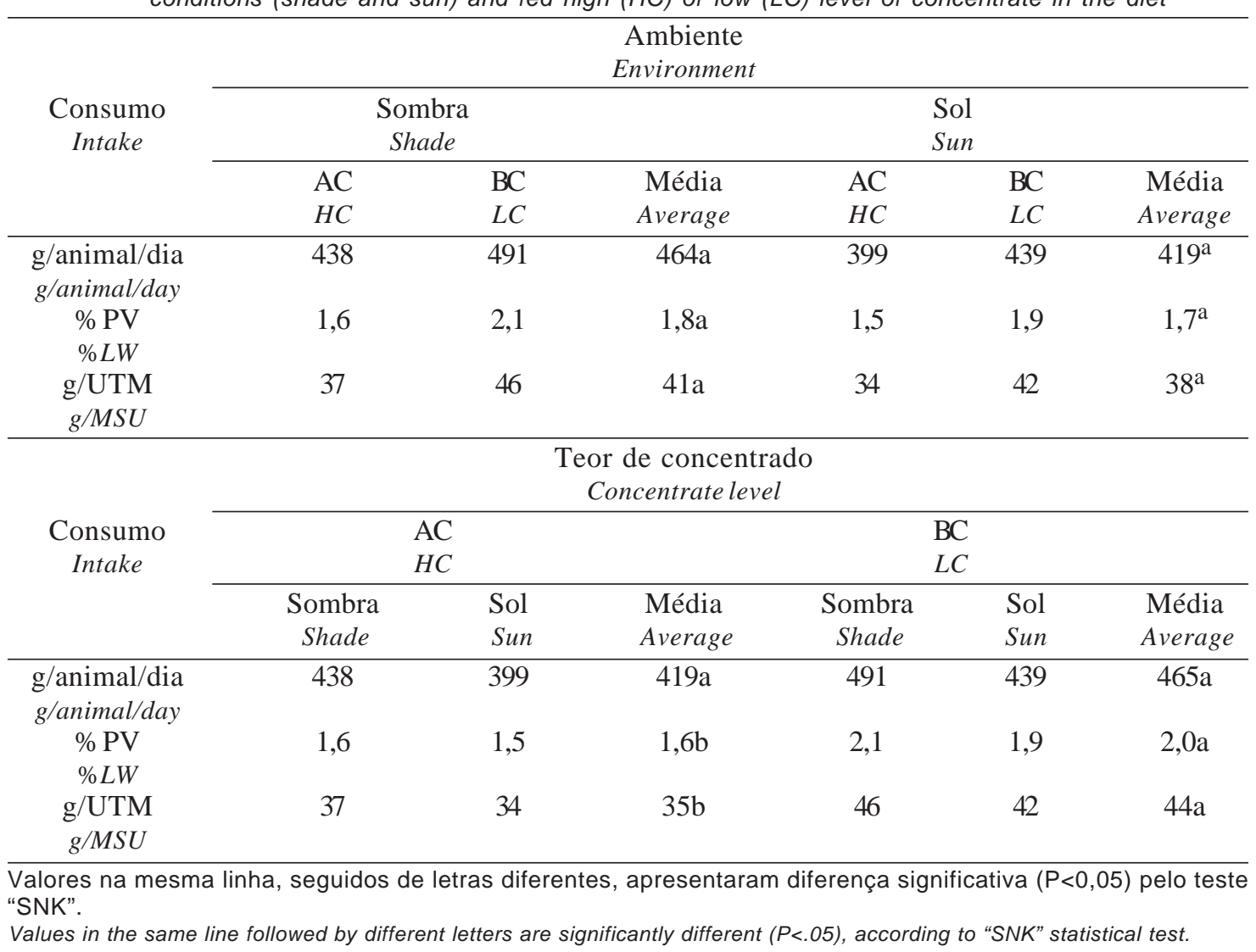

R. Bras. Zootec., v.33, n.3, p.668-678, 2004 
maximização da produção.

Esses resultados diferem dos encontrados por Padua \& Silva (1996) e Dixon et al. (1999), que não observaram diferenças significativas $(\mathrm{P}>0,05)$ entre os ganhos de peso, devido ao efeito do ambiente. No entanto, estão de acordo com os resultados encontrados por Huertas et al. (1974) e Ames \& Brink (1977).

Os animais alimentados com dietas contendo alto teor de ração concentrada apresentaram ganho de peso significativamente maior $(\mathrm{P}<0,05)$ (Tabela 6$)$ que os alimentados com dietas de baixo teor. Tal resultado era esperado, pois as dietas com baixo teor de ração concentrada não atendiam às exigências nutricionais mínimas dos animais (NRC, 1985).

\section{Parâmetros bioclimatológicos e fisiológicos}

As médias de temperatura ambiente, umidade relativa do ar e índice de temperatura e umidade observadas durante o ensaio bioclimatológico, nos períodos da manhã e da tarde e nas duas condições de instalação testadas, são descritas na Tabela 7.

Os valores de temperatura ambiente encontrados superaram a temperatura crítica de 24 e $27^{\circ} \mathrm{C}$, para a maioria das espécies, segundo Fuquay (1981). Tal fato ocorreu durante a manhã para a condição de exposição direta à radiação solar e pela tarde, tanto para as baias à sombra como para as baias ao sol. Quando comparados aos valores obtidos por Alexander \& Williams (1961), citados por Hassanin (1996), que apontam valores de 25 a $30^{\circ} \mathrm{C}$ como a temperatura ideal para cordeiros, observou-se que as temperaturas encontradas superaram os valores de temperatura de conforto durante a tarde, sendo que as baias protegidas da radiação solar direta superaram este limite em apenas $0,6^{\circ} \mathrm{C}$.

Com relação ao ITU, os valores encontrados demonstram que nas duas condições ambientais (sol ou sombra) os animais foram submetidos a algum nível de estresse; na sombra, provavelmente devido à condição de alta umidade, e no sol, devido à alta carga

Tabela 5 - Consumo médio diário de água de ovinos da raça Santa Inês confinados sob sol ou sombra e alimentados com dietas contendo alto (AC) e baixo (BC) teor de ração concentrada

Table 5 - Average daily water intake by Santa Inês rams raised under two housing conditions (shade and sun) and fed high (HC) or low (LC) level of concentrate in the diet

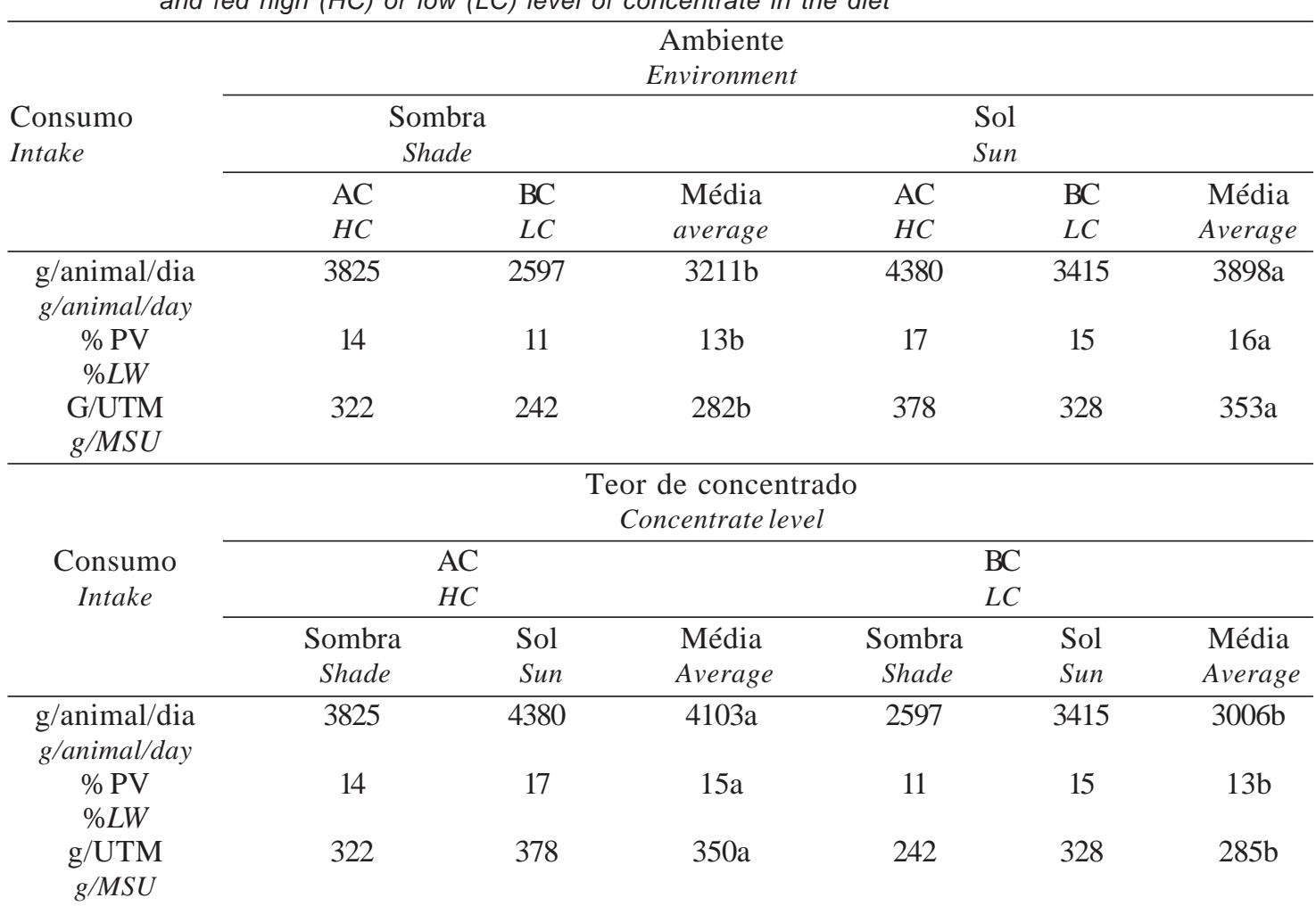

Valores na mesma linha, seguidos de letras diferentes, apresentaram diferença significativa $(P<0,05)$ pelo teste "SNK".

Values in the same line followed by different letters are significantly different $(P<.05)$, according to "SNK" statistical test.

\section{R. Bras. Zootec., v.33, n.3, p.668-678, 2004}


térmica recebida. Comparando com os valores de ITU apresentados por Hahn (1985), citado por Barbosa (1995)(Tabela 8), observou-se que, durante a manhã, os animais mantidos à sombra estiveram dentro do limite crítico e os mantidos ao sol, em zona de perigo. Durante a tarde, tanto as baias mantidas ao sol quanto as mantidas à sombra estiveram dentro da faixa de perigo. Destaca-se ainda que os animais mantidos ao sol durante o período da tarde não alcançaram a zona de emergência por apenas 0,7
(ITU > 83), portanto em condição de elevado estresse.

Já a freqüência respiratória dos animais mantidos à sombra e alimentados com dietas com alto teor de ração concentrada foi superior $(\mathrm{P}<0,05)$ à freqüência respiratória daqueles alimentados com dietas contendo baixo teor de ração concentrada em ambos ambientes estudados. No entanto, não se observou diferença $(\mathrm{P}>0,05)$ entre os animais alimentados com dietas com alto teor de ração concentrada, quando mantidos ao sol ou à sombra (Tabela 9).

Tabela 6 - Ganho de peso médio diário (GMD) de ovinos da raça Santa Inês confinados sob condições de sol ou sombra e alimentados com dietas contendo alto (AC) e baixo (BC) teor de ração concentrada

Table 6 - Weight gain of Santa Inês rams fed high (HC) or low (LC) level of concentrate and raised under shade or sun

\begin{tabular}{|c|c|c|c|c|c|c|}
\hline & \multicolumn{6}{|c|}{$\begin{array}{c}\text { Ambiente } \\
\text { Environment }\end{array}$} \\
\hline & \multicolumn{2}{|c|}{$\begin{array}{l}\text { Sombra } \\
\text { Shade }\end{array}$} & \multicolumn{4}{|c|}{$\begin{array}{l}\text { Sol } \\
\text { Sun }\end{array}$} \\
\hline & AC & $\mathrm{BC}$ & Média & AC & $\mathrm{BC}$ & Média \\
\hline & $H C$ & $L C$ & Average & $H C$ & $L C$ & Average \\
\hline \multirow[t]{4}{*}{$\begin{array}{l}\text { g/animal/dia } \\
\text { g/animal/day }\end{array}$} & 247 & 100 & $174 a$ & 180 & 64 & $122 b$ \\
\hline & \multicolumn{5}{|c|}{$\begin{array}{l}\text { Teor de concentrado } \\
\text { Concentrate level }\end{array}$} & \\
\hline & & & $\begin{array}{c}\text { Média } \\
\text { Average }\end{array}$ & & & $\begin{array}{c}\text { Média } \\
\text { Average }\end{array}$ \\
\hline & $\begin{array}{c}\text { Sombra } \\
\text { Shade }\end{array}$ & $\begin{array}{l}\text { Sol } \\
\text { Sun }\end{array}$ & & $\begin{array}{c}\text { Sombra } \\
\text { Shade }\end{array}$ & $\begin{array}{l}\text { Sol } \\
\text { Sun } \\
\end{array}$ & \\
\hline $\begin{array}{l}\text { g/animal/dia } \\
\text { g/animal/day }\end{array}$ & 247 & 180 & $214 a$ & 100 & 64 & $82 b$ \\
\hline
\end{tabular}

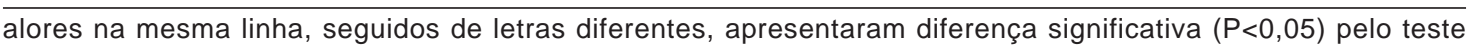
"SNK".

Values in the same line followed by different letters are significantly different $(P<.05)$, according to "SNK" statistical test.

Tabela 7 - Médias de temperatura ambiente, umidade relativa e índice de temperatura e umidade nos dois períodos do dia e nas duas condições de instalação

Table 7 - Averages for air temperature, humidity and temperature-humidity index in two periods of the day and housing conditions

\begin{tabular}{|c|c|c|c|c|c|c|}
\hline $\begin{array}{c}\text { Condição } \\
\text { Housing }\end{array}$ & $\begin{array}{l}\mathrm{TA}_{\mathrm{M}}\left({ }^{\circ} \mathrm{C}\right) \\
A T_{M}\left({ }^{\circ} \mathrm{C}\right)\end{array}$ & $\begin{array}{c}\mathrm{TA}_{\mathrm{T}}\left({ }^{\circ} \mathrm{C}\right) \\
A T_{T}\left({ }^{\circ} \mathrm{C}\right)\end{array}$ & $\begin{array}{l}\mathrm{UR}_{\mathrm{M}}(\%) \\
R U_{M}(\%)\end{array}$ & $\begin{array}{l}\mathrm{UR}_{\mathrm{T}}(\%) \\
R U_{M}(\%)\end{array}$ & $\begin{array}{l}\mathrm{ITU}_{\mathrm{M}} \\
\mathrm{THI}_{M}\end{array}$ & $\begin{array}{c}\mathrm{ITU}_{\mathrm{T}} \\
\mathrm{THI}_{T}\end{array}$ \\
\hline $\begin{array}{l}\text { Sombra } \\
\text { Shade }\end{array}$ & 26,9 & 30,6 & 82,1 & 66,6 & 77,6 & 81,1 \\
\hline $\begin{array}{l}\text { Sol } \\
\text { Sun }\end{array}$ & 28,7 & 32,1 & 71,2 & 60,5 & 79,0 & 82,3 \\
\hline
\end{tabular}

$\overline{\operatorname{TA}_{M}\left({ }^{\circ} \mathrm{C}\right): \text { Temperatura ambiente pela manhã; } \mathrm{TA}_{\mathrm{T}}\left({ }^{\circ} \mathrm{C}\right): \text { Temperatura ambienta à tarde; } \mathrm{UR}_{\mathrm{M}}}$ (\%): Umidade relativa pela manhã; $U_{T}(\%)$ : Umidade relativa à tarde; ITU $\mathrm{M}_{\mathrm{M}}$ :Índice de temperatura e umidade pela manhã; ITU : Índice de temperatura e umidade à tarde.

$A T_{M}\left({ }^{\circ} \mathrm{C}\right)$ : Air temperature in the morning; $A T_{T}\left({ }^{\circ} \mathrm{C}\right)$ : Air temperature in the afternoon; $R U_{M}(\%)$ : Relative

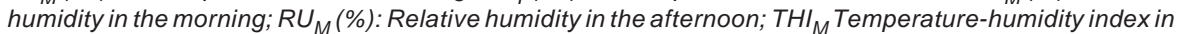
the morning; $\mathrm{THI}_{T}$ Temperature-humidity index in the afternoon.

R. Bras. Zootec., v.33, n.3, p.668-678, 2004 
Para as dietas com baixo teor de ração concentrada, observou-se diferença significativa $(\mathrm{P}<0,05)$ entre as duas condições ambientais, sendo que os animais alimentados com essas dietas e mantidos ao sol apresentaram freqüência respiratória superior àqueles alimentados com a mesma dieta, porém mantidos à sombra. Provavelmente, os animais mantidos à sombra e alimentados com dietas contendo alto teor de ração concentrada apresentaram maior freqüência respiratória, como resultado do nível de energia da dieta e do alto consumo de matéria seca pelos animais, proporcionando elevado incremento calórico, o que não ocorreu com os animais mantidos à sombra e alimentados com dieta contendo baixo teor de ração concentrada.

Com relação aos animais mantidos ao sol, a justificativa para os valores encontrados é o nível de estresse ao qual foram submetidos, pois não se mostraram capazes de dissipar toda a carga calórica recebida no dia anterior. Deve-se destacar ainda que o elevado consumo de MS, com certeza, aumentou o incremento calórico e acentuou o estresse dos animais. Por outro lado, os animais mantidos à sombra e alimentados com dieta com baixo teor de ração concentrada, pela condição ambiental e pelo consumo de uma dieta que não proporcionou incremento calórico significativo, não tiveram a freqüência respiratória elevada significativamente $(\mathrm{P}>0,05)$. Estes resultados diferiram dos encontrados por Bhattacharya \& Hussain (1974), que observaram aumento mais pronunciado na atividade respiratória dos animais sob estresse e alimentados com alta proporção de volumoso na dieta (75\%).

Os animais mantidos ao sol apresentaram os maiores valores de freqüência respiratória durante a tarde, independentemente do teor de ração concentrada da dieta, resultado justificado pela alta carga calórica recebida durante o dia (Tabela 9). A freqüência respiratória dos animais mantidos ao sol pela manhã foi semelhante à freqüência dos mantidos à sombra durante os períodos da manhã e da tarde, independentemente do teor de ração concentrada da dieta. Tal semelhança se justifica pelo fato de, durante o período da manhã, os animais mantidos ao sol ainda não terem sido submetidos à alta carga calórica, sendo tal nível de estresse referente ao incremento calórico proporcionado pelas dietas.

Os animais mantidos à sombra apresentaram temperatura retal média superior aos animais mantidos ao sol, independentemente da dieta fornecida e do período de coleta dos dados, provavelmente devido ao efeito do incremento calórico proporcionado pela dieta e do alto nível de consumo de matéria seca (1062 g/animal/dia; Tabela 4). Este resultado diferiu do encontrado por Souto et al. (1990), que observaram diferença significativa na temperatura retal dos animais mantidos em condições ambientais diferentes, recebendo dietas de composições diferentes.

Os animais alimentados com dieta contendo alto teor de ração concentrada apresentaram temperatura retal significativamente maior $(\mathrm{P}<0,05)$, independentemente

Tabela 8 - Índice de temperatura e umidade (ITU) para animais ruminantes

Table 8 - Temperature-humidity index (THI) for ruminants

\begin{tabular}{ccccc}
\hline ITU & $<70$ & $71-78$ & $79-83$ & $>83$ \\
THI & & & & \\
\hline $\begin{array}{c}\text { Condição } \\
\text { Housing }\end{array}$ & Normal & Crítica & $\begin{array}{c}\text { Perigo } \\
\text { Danger }\end{array}$ & $\begin{array}{c}\text { Emergência } \\
\text { Emergency }\end{array}$ \\
\hline
\end{tabular}

Fonte: Hahn (1985), citado por Barbosa (1995).

Source: Hahn (1985), cited by Barbosa (1995).

Tabela 9 - Freqüência respiratória (FR) de ovinos Santa Inês confinados sob sol ou sombra, alimentados com dietas contendo alto (AC) e baixo (BC) teor de concentrado nos períodos da manhã e tarde

Table 9 - Respiratory frequency (RF), in the morning and afternoon, in feedlot Santa Inês rams raised under shade or sun and fed diets with high (HC) and low (LC) concentrate

\begin{tabular}{|c|c|c|c|c|}
\hline \multirow{4}{*}{$\begin{array}{l}\text { Variável } \\
\text { Variable }\end{array}$} & \multicolumn{4}{|c|}{$\begin{array}{c}\text { Ambiente } \\
\text { Housing conditions }\end{array}$} \\
\hline & \multicolumn{2}{|c|}{$\begin{array}{c}\text { Sombra } \\
\text { Shade }\end{array}$} & \multicolumn{2}{|c|}{$\begin{array}{l}\text { Sol } \\
\text { Sun }\end{array}$} \\
\hline & AC & $\mathrm{BC}$ & AC & $\mathrm{BC}$ \\
\hline & $H C$ & $L C$ & $H C$ & $L C$ \\
\hline \multirow{4}{*}{$\begin{array}{c}\mathrm{FR}^{*} \\
R F\end{array}$} & $87 a$ & $32 c$ & 71ab & $65 b$ \\
\hline & \multicolumn{4}{|c|}{$\begin{array}{c}\text { Ambiente } \\
\text { Housing conditions }\end{array}$} \\
\hline & \multicolumn{2}{|c|}{$\begin{array}{c}\text { Sombra } \\
\text { Shade }\end{array}$} & \multicolumn{2}{|c|}{$\begin{array}{l}\text { Sol } \\
\text { Sun }\end{array}$} \\
\hline & $\begin{array}{l}\text { Manhã } \\
\text { Morning }\end{array}$ & $\begin{array}{c}\text { Tarde } \\
\text { Afternoon }\end{array}$ & $\begin{array}{l}\text { Manhã } \\
\text { Morning }\end{array}$ & $\begin{array}{c}\text { Tarde } \\
\text { Afternoon }\end{array}$ \\
\hline $\begin{array}{l}\mathrm{FR}^{*} \\
R F\end{array}$ & $59 b$ & $60 \mathrm{~b}$ & $45 b$ & $91^{\mathrm{a}}$ \\
\hline
\end{tabular}

Valores na mesma linha, seguidos de letras diferentes, apresentaram diferença significativa $(P<0,05)$ pelo teste "SNK".

Values in the same line followed by different letters are significantly different $(P<.05)$, according to "SNK" statistical test. 
da condição de instalação e do período de coleta dos dados, confirmando o alto incremento calórico proporcionado pela dieta (Tabela 10).

A elevação da temperatura ambiente no decorrer do dia exerceu efeito sobre a temperatura retal dos animais, de forma que, durante o período da tarde, o valor médio foi significativamente superior $(\mathrm{P}<0,05)$ ao da manhã, independentemente da condição de instalação e da dieta fornecida (Tabela 10).

A partir dos resultados encontrados, observa-se que a temperatura retal não foi uma variável sensível para detecção de estresse ambiental tanto quanto o foi a freqüência respiratória, pois não foram encontradas diferenças significativas entre as combinações das variáveis (condição de instalação x teor de ração concentrada da dieta $\mathrm{x}$ período de coleta dos dados). Esta observação está de acordo com os estudos de Kaushish \& Sahni (1975), que registraram maior sensibilidade da freqüência respiratória às oscilações térmicas, e os de Bhattacharya \& Uwayjan (1975), que também não registraram diferenças significativas para temperatura retal dos animais

Tabela 10 - Temperatura retal (TR) de ovinos Santa Inês confinados sob sol ou sombra, alimentados com dietas contendo alto (AC) e baixo (BC) teor de concentrado nos períodos da manhã e tarde

Table 10 - Rectal temperature (RT), in the morning and afternoon, in feedlot Santa Inês rams raised under shade or sun and fed diets with high (HC) and low (LC) concentrate

\begin{tabular}{|c|c|c|}
\hline \multirow{2}{*}{$\begin{array}{l}\text { Variável } \\
\text { Variable }\end{array}$} & \multicolumn{2}{|c|}{$\begin{array}{c}\text { Ambiente } \\
\text { Housing conditions }\end{array}$} \\
\hline & $\begin{array}{l}\text { Sombra } \\
\text { Shade }\end{array}$ & $\begin{array}{l}\text { Sol } \\
\text { Sun }\end{array}$ \\
\hline \multirow{8}{*}{$\begin{array}{c}\mathrm{TR}\left({ }^{\circ} \mathrm{C}\right) \\
R T\end{array}$} & $39,1 \mathrm{a}$ & $38,9 b$ \\
\hline & \multicolumn{2}{|c|}{$\begin{array}{c}\text { Período } \\
\text { Period }\end{array}$} \\
\hline & $\begin{array}{l}\text { Manhã } \\
\text { Morning }\end{array}$ & $\begin{array}{c}\text { Tarde } \\
\text { Afternoon }\end{array}$ \\
\hline & $38,9 b$ & $39,1 \mathrm{a}$ \\
\hline & \multicolumn{2}{|c|}{$\begin{array}{c}\text { Dieta } \\
\text { Diet }\end{array}$} \\
\hline & $\mathrm{AC}$ & $\mathrm{BC}$ \\
\hline & $H C$ & $L C$ \\
\hline & $39,2 \mathrm{a}$ & $38,8 b$ \\
\hline
\end{tabular}

alores na mesma linha, seguidos de letras diferentes, apresentaram diferença significativa $(P<0,05)$ pelo teste "SNK".

Values in the same line followed by different letters are significantly different $(P<.05)$, according to "SNK" statistical test.

R. Bras. Zootec., v.33, n.3, p.668-678, 2004 mantidos em condições de temperatura e umidade semelhantes ao do presente trabalho. No entanto, no caso do presente experimento, outra justificativa para tal fato está associada ao fato de a avaliação de desempenho produtivo ter sido realizada antes do ensaio bioclimatológico, possibilitando um período de aclimatação dos animais, o que possivelmente influenciou o comportamento animal, não se permitindo detectar interação.

Já Dixon et al. (1999) encontraram diferença significativa entre as temperaturas retais médias dos animais mantidos em diferentes condições ambientais e alimentados com dietas contendo vários níveis de ração concentrada, diferindo dos resultados encontrados no presente ensaio, que não registraram diferença significativa entre as combinações das variáveis.

Os valores de temperatura retal encontrados foram semelhantes aos destacados por Singh \& Acharya (1977) e inferiores aos valores de frequência respiratória, sob condição ambiental mais estressante. Resultados semelhantes foram observados por Hopkins (1978) e por Gupta \& Acharya (1987). A temperatura retal encontrada por Brown (1971) foi superior à registrada nos ovinos avaliados no presente trabalho.

Souza et al. (1990) registraram valores semelhantes para temperatura retal, porém menores para frequência respiratória, em ovinos da raça Santa Inês.

Semelhantemente aos resultados obtidos por Brosh et al. (1998), as frequências respiratórias nos dois períodos do dia e as temperaturas retais durante a manhã, sofreram efeito do nível de energia da dieta e da condição de instalação. Isto só não foi verificado com a temperatura retal durante a tarde, pois esta não sofreu efeito de ambos os fatores.

\section{Conclusões}

Os animais da raça Santa Inês mostraram-se sensíveis ao estresse ambiental, uma vez que apresentaram menor desempenho produtivo quando mantidos ao sol, não atingindo o ganho de peso máximo, mesmo se alimentados com dietas com alta concentração de nutrientes.

O clima tropical quente e úmido, característico da região litorânea do Ceará, proporciona condições críticas para o conforto dos animais, evidenciadas pelos valores do índice de temperatura e umidade, embora a presença de sombra nas instalações possa amenizar estes efeitos. 
O tipo de dieta influenciou de forma significativa a susceptibilidade dos animais ao estresse causado por essas condições ambientais. Portanto, mesmo no caso de animais deslanados de raças originárias de regiões tropicais, como a Santa Inês, as interações entre tipo de alimento, consumo, ambiente e parâmetros fisológicos devem ser determinadas, a fim de que o desempenho dos animais não seja prejudicado.

\section{Literatura Citada}

AMES, D.R.; BRINK, D.R. Effect of temperature on lamb performance and protein efficiency ratio. Journal of Animal Science, v.44, n.1, p.136-140, 1977.

BAETA, F.C.; SOUZA, C.F. Ambiência em edificações rurais: conforto animal. Viçosa, MG: Universidade Federal de Viçosa, 1997. 246p.

BARBOSA, O.R.; SILVA, R.G. Índice de conforto térmico para ovinos. In: REUNIÃO ANUAL DA SOCIEDADE BRASILEIRA DE ZOOTECNIA, 32., 1995, Brasília. Anais... Brasília: Sociedade Brasileira de Zootecnia, 1995. p.141-143.

BHATTACHARYA, A. N., HUSSAIN, F. Intake and utilization of nutrients in sheep fed different levels of roughage under heat stress. Journal of Animal Science, v.38, n.4, p.877-886, 1974.

BHATTACHARYA, A.N.; UWAYJAN, M. Effect of high ambient temperature and low humidity on nutrient utilization and on some physiological responses in Awasi sheep fed different levels of roughage. Journal of Animal Science, v.40, n.2, p.320-328, 1975.

BROSH, A.; AHARONI, Y.; DEGEN, A.A. et al. Effects of solar radiation, dietary energy, and time of feeding on thermoregulatory responses and energy balance in cattle in a hot environment. Journal of Animal Science, v.76, p.2671-2677, 1998.

BROWN, G.D. Thermal status of sheep at pasture in western New South Wales. Australian Journal of Agricultural Research, v.22, p.797-808, 1971.

COSTA, M.J.R.; SILVA, R.G.; SOUZA, R.C. Effect of air temperature and humidity on ingestive behaviour of sheep. International Journal Biometeorology, v.36, p.218-222, 1992.

DIXON, R.M.; THOMAS, R.; HOLMES, J.H.G. Interactions between heat stress and nutrition in sheep fed roughage diets. Journal of Agricultural Science, v.132, p.351-359, 1999.

FUQUAY, J.W. Heat stress as it affects animal production. Journal of Animal Science, v.52, n.1, p.164-174, 1981.

GUPTA, U.D.; ACHARYA, R.M. Heat tolerance in different genetic groups of sheep in semi-arid conditions. Indian Journal of Animal Science, v.57, n.12, p.1314-1318, 1987.

HASSANIN, H.S.; ABDALLA, E.B.; KOTBY, E.A. et al. Efficiency of asbestos shading for growth of Barki rams during hot summer. Small Ruminant Research, v.20, p.199-203, 1996.

HOPKINS, P.S.; KNIGHTS, G.I.; Le FEUVRE, A.S. Studies of the environmental physiology of tropical Merinos. Australian Journal Agricultural Research, v.29, p.161-171, 1978.
HUERTAS, A.A.G.; SILVA, J.F.C.; CAMPOS, O.F. et al. Efeito da temperatura ambiente sobre o consumo, digestibidade e a retenção dos nutrientes em ovinos. Revista da Sociedade Brasileira Zootecnia, v.3, n.2, p.245-268, 1974.

KAUSHISH, S.K.; SAHNI, K.L. Seasonal variation in rectal temperature and pulse and respiration.rates of Russian Merino sheep in semi-arid climate. Indian Journal of Animal Science, v.45, n.11, p.860-863, 1975.

McDOWELL, R.E. Bases biológicas de la producción animal em zonas tropicales. 1.ed. Zaragoza: Acribia, 1974. 692p.

MENDES, M.A.; LEÃO, M.I.; SILVA, J.F.C. et al. Efeito da temperatura ambiente e do teor de energia da ração sobre os consumos de alimentos e de água e algumas variáveis fisiológicas de ovinos. Revista da Sociedade Brasileira Zootecnia, v.5, n.2, p.173-187, 1976a.

MENDES, M.A.; LEÃO, M.I.; SILVA, J.F.C. et al. Efeito de diferentes níveis de energia em rações para ovinos submetidos a temperatura ambiente elevada $\left(32-35^{\circ} \mathrm{C}\right)$, sobre os coeficientes de digestibilidade aparente, consumo e retenção de nutrientes. Revista da Sociedade Brasileira Zootecnia, v.5, n.2, p.248-258, 1976b.

NATIONAL RESEARCH COUNCIL - NRC. Nutrient requirements of sheep. 6.ed. Washington, D.C.: National Academy Press, 1985. 112p.

PADUA, J.T.; SILVA, R.G. Efeito do estresse térmico sobre o desempenho e características fisiológicas em borregos Ideal. In: REUNIÃO ANUAL DA SOCIEDADE BRASILEIRA DE ZOOTECNIA, 33., 1996, Fortaleza. Anais... Fortaleza: Sociedade Brasileira de Zootecnia, 1996. v.1, p.657-659.

STATISTICAL ANALYSIS SYSTEM - SAS. User's guide. Cary: 1990.

SINGH, M.; ACHARYA, R.M. A note on the mode of heat dissipation in different types of sheep. Indian. Journal Animal Science, v.47, n.6, p.367-368, 1977.

SOUTO, P.R.L.; MILAGRES, J.C.; SILVA, J.F.C. Consumo, digestibilidade, reações fisiológicas e componentes sanguíneos de ovinos submetidos a diferentes temperaturas e a dietas com diferentes níveis de energia. II - Reações fisiológicas. Pesquisa Agropecuária Brasileira, v.25, n.9, p.1253-1259, 1990b.

SOUZA, B.B.; SILVA, A.M.A.; VIRGÍNIO, R.S. et al. Comportamento fisiológico de ovinos deslanados no semi-árido expostos em ambiente de sol e em ambiente de sombra. Veterinária e Zootecnia, v.2, p.1-7, 1990.

Van SOEST, P. Nutritional ecology of the ruminant. O \& B Books Corvallis: Oregon, 1982. 267p.

YOUNG, B. A. Effect of environmental stress on nutrient needs. In: CHURCH, D.C. (Ed.) The ruminant animal. New Jersey: Prentice Hall, 1988. p.456-467. 